\title{
Comparison of Signal Powers Generated with Different Shapes of Hammer Plates
}

\author{
Ji-Hyun Jeong and Jin-Hoo Kim* \\ Department of Energy and Mineral Resources Engineering, Dong-A University, \\ Busan 604-714, Korea
}

\begin{abstract}
One of the main problems concerning the shallow seismic survey is how to generate high frequency signals with large amplitudes using small seismic sources. If one could focus the seismic energy in the direction of the survey line, it will be much helpful in identifying the first break. In this research, we have used hammer as an impulsive source and compared the signal powers generated by different shapes of the hammer plates: circular, square, and rectangular. The experiment was conducted by calculating the power spectral density function to compare the frequency spectrum and signal power. In the direction perpendicular to the long side of the rectangular plate, the largest seismic energy with the highest frequency was achieved even with the same weights of hammer plates. Our conclusion is that it is more efficient to use a rectangular plate than a circular (or square) one when conducting a 2-D shallow seismic survey.
\end{abstract}

Keywords: seismic survey, hammer, plate shapes, Power Spectral Density (PSD), signal power

\section{Introduction}

Choosing the seismic source in shallow seismic survey is probably one of the most significant factors in determining the success of the survey. Because seismic source type is directly related to the survey environment, the following criteria must be met. The seismic wave that returns to the surface refracted or reflected after being propagated all the direction to the target depth must have sufficient energy, and its frequency band must be high enough and its spectrum should be wide enough to allow adequate resolution for the interpretation of data. Besides energy and the shape of frequency spectrum of the source, coherency and signal-to-noise ratio must be taken into account as well as convenience of use, safety and repeatability (Knapp and Steeples, 1986; Milsom, 2008).

A number of studies conducted previously (Miller et al., 1986; Hearn and Kay, 1991; Miller et al., 1992, 1994; Buhnemann and Holliger, 1998; Doll et al., 1998 etc.) attempted to compare the energy and power spectrum of various sources including explosive and

*Corresponding author: jkim@dau.ac.kr

Tel: +82-51-200-7790

Fax: +82-51-200-7771 non-explosive sources, although most of them focused on the source characteristics in specific areas. Likewise Kim et al. (1994a) have also successfully managed to improve field applicability and signal-tonoise ratio by developing a non-explosive seismic source of weight drop type. Recently, Kim and Lee (2011) have shown that plastic hammer plates can be used instead of aluminum plates for shallow seismic surveys.

When conducting a small scale 2-D seismic survey, the source and geophone are generally arrayed in a straight line. Therefore, if most of the seismic energy generated by a small source such as hammer is propagated in the direction of the geophone array, the problem of insufficient energy being generated could be solved. By using source array, Kim et al. (1994b) have demonstrated the energy effect of P-waves enhancement and surface waves decrease by field experiment. Prior to this study, Mereu et al. (1963) have considered an experimental process where impulsive energy transforms into elastic energy by the plate, as well as the change in the amplitude of seismic wave depending on various combination of weight and plate. However, because only a spherical plate was used, there is no study of energy directivity.

The intent of this paper is to develop a method to 
enhance energy being generated, by analyzing the direction of the geophone array using hammer and plate. Three different shapes of plates-circular, square, rectangular with the same weight were investigated to elucidate wave propagation characteristics and power spectrum.

\section{Methods}

\section{Hammer Plate}

The seismic signal powers were compared for three kinds of shapes (circular, square, rectangular) made from polyethylene, a kind of industrial plastic. Mereu et al. (1963) showed the following relation

$$
\begin{aligned}
& A \propto M^{2 / 3} V_{c} \\
& V_{c}=(1+e) \frac{m}{m+M} u
\end{aligned}
$$

holds for the seismic wave amplitude (A) caused by the plate with mass $(\mathrm{M})$, and the maximum impact velocity $\left(V_{\mathrm{c}}\right)$. The $e$ indicates the rebound coefficient between the hammer and the plate, $m$ indicates the mass of the hammer, and $u$ indicates the velocity of the hammer on impact. As can be seen from equation (1), the amplitude of the seismic wave is proportional to the product of the plate mass and its maximum velocity, and the maximum velocity of the plate is closely related to the mass and velocity of the hammer, and the rebound coefficient between the hammer and the plate.

In this study, the same hammer was dropped from the same height, $m$ and $u$ were set constant, and the value of $e$ was also maintained constant by using the same kind of material for the plate. In addition, the base area, height, and mass $M$ were set the same in spite of the different shapes (Fig. 1).

Table 1 shows the size and material properties of plates. The P- and S-wave velocities of the plate were measured using ultrasonic velocity meter (SonicViewer 170, OYO Corp.). The rebound coefficient of the plate was calculated by taking the ratio of the rebounding height ( $h$ ') to the falling height (h) as follow:

$$
\text { Rebound Coefficient }=\sqrt{\frac{h^{\prime}}{h}}
$$

Falling and rebounding height were measured by capturing an image taken from a high speed motion picture camera (Phantom Miro eX2, Komi Co.) that takes 1,000 frames of pictures per second. During the measurement the plate was fixed on a concrete floor and a $1 \mathrm{~kg}$ hammer was dropped from approximately $50 \mathrm{~cm}$ above it in a free fall.

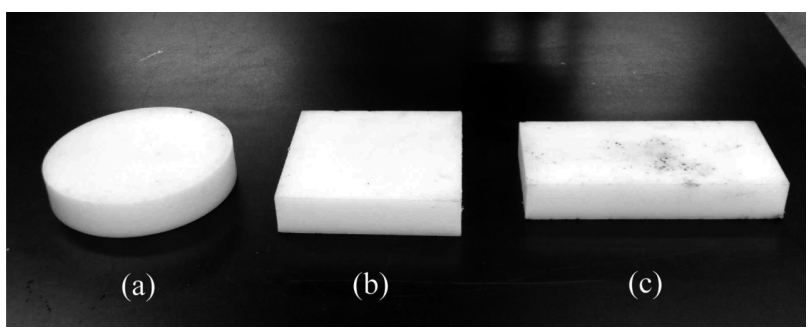

Fig. 1. Different shapes of hammer plates: (a) circular, (b) square and (c) rectangular plate.

Table 1. Material properties of plates

\begin{tabular}{cccccc}
\hline \hline $\begin{array}{c}\text { Plate } \\
\text { Shapes }\end{array}$ & $\begin{array}{c}\text { Size } \\
(\mathrm{W} \times \mathrm{D} \times \mathrm{H}) \\
(\mathrm{cm})\end{array}$ & $\begin{array}{c}\text { Mass } \\
(\mathrm{kg})\end{array}$ & $\begin{array}{c}\mathrm{V}_{\mathrm{p}} \\
(\mathrm{km} / \mathrm{sec})\end{array}$ & $\begin{array}{c}\mathrm{V}_{\mathrm{s}} \\
(\mathrm{km} / \mathrm{sec})\end{array}$ & $\begin{array}{c}\text { Rebound } \\
\text { Coefficient }\end{array}$ \\
\hline Circular & $\phi 25 \times 5$ & 2.37 & & & \\
\hline Square & $22 \times 22 \times 5$ & 2.34 & 2.49 & 0.98 & 0.79 \\
\cline { 1 - 2 } Rectangular & $31.5 \times 15.55 \times 5$ & 2.36 & & & \\
\hline
\end{tabular}




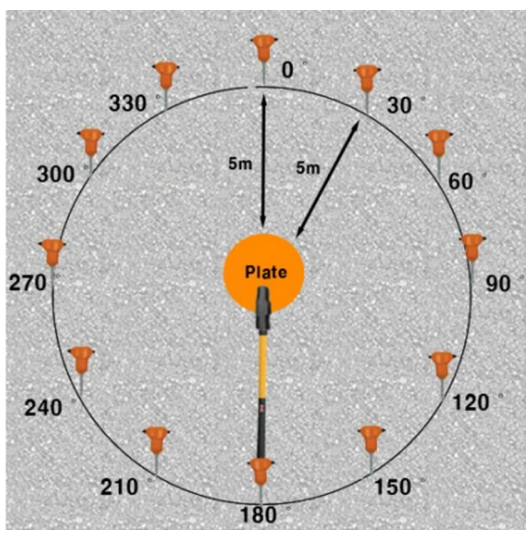

Fig. 2. A schematic drawing of seismic data acquisition setup. A 5-m circular geophone array is used. The long side of the rectangular plate and the side of the square plate are heading to the geophone at $0^{\circ}$. The hammer blowing direction is pointing to the geophone at $0^{\circ}$.

\section{Data Acquisition}

In order to measure the propagation characteristics of the seismic waves depending on the shapes of the plates, data were acquired using two kinds of geophone array, (1) a circular geophone array and (2) a linear geophone array.

Circular geophone array installed the geophone at $30^{\circ}$ intervals with $5 \mathrm{~m}$ offset from the source (Fig. 2). If the ground is homogeneous and a circular plate is used, the same intensity of energy is expected to propagate in all directions. However, if a square or a rectangular plate is used, the result will be different and circular geophone array will have to be used to find out in which direction the propagated energy is more focused.

Linear geophone array installed the geophone at 3 $\mathrm{m}$ intervals with $3 \mathrm{~m}$ offset from the source (Fig. 3). This is so as to find out the shape and orientation of the plate that will receive the maximum energy even when the ground is inhomogeneous by changing the direction of the plate.

For all the cases, an $8.2 \mathrm{~kg}$ sledge hammer is dropped at the height of $0.7 \mathrm{~m}$ with placing the hammer handle at the hinge axis allowing the hammer to hit the center of the plate. The seismic waves are received by vertical geophone $(28 \mathrm{~Hz})$ and 12-channel seismograph (Geode, Geometrics Ltd.) with analog filters open.

\section{Results and Discussion}

\section{Comparison of signal powers depending on the direction of wave propagation}

Figure 4 showed the same signal power by a circular plate and different by square or rectangular plate.

Figure 5 showed a radial graph of signal powers by square and rectangular plates with respect to the circular plate for comparison. Although less signal power is observed for the square plate than the circular one in $120^{\circ}$ and $240^{\circ}$ direction, approximately $10-20 \%$ more signal power is observed in the direction of $0^{\circ}$ and $180^{\circ}$. Generally a rectangular plate generates more energies, particularly the maximum signal power was achieved when geophone is installed perpendicular to the long side of the plate.

\section{Comparison of signal powers depending on the rotation of the rectangular plate}

The relationship between the signal Power Spectral Density (PSD), signal power and the rotating angle of the plate were observed for a linear geophone array. PSD is obtained by covariance method which utilizes

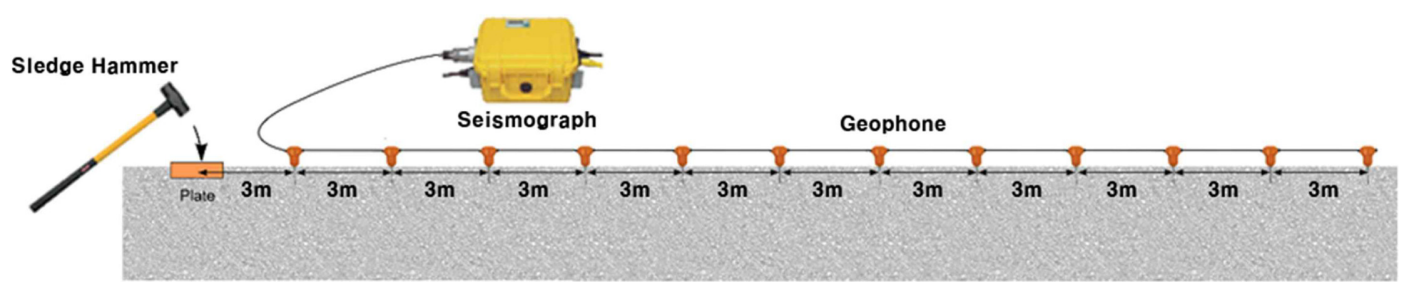

Fig. 3. A schematic drawing of seismic data acquisition setup. A 36-m linear geophone array is used. 


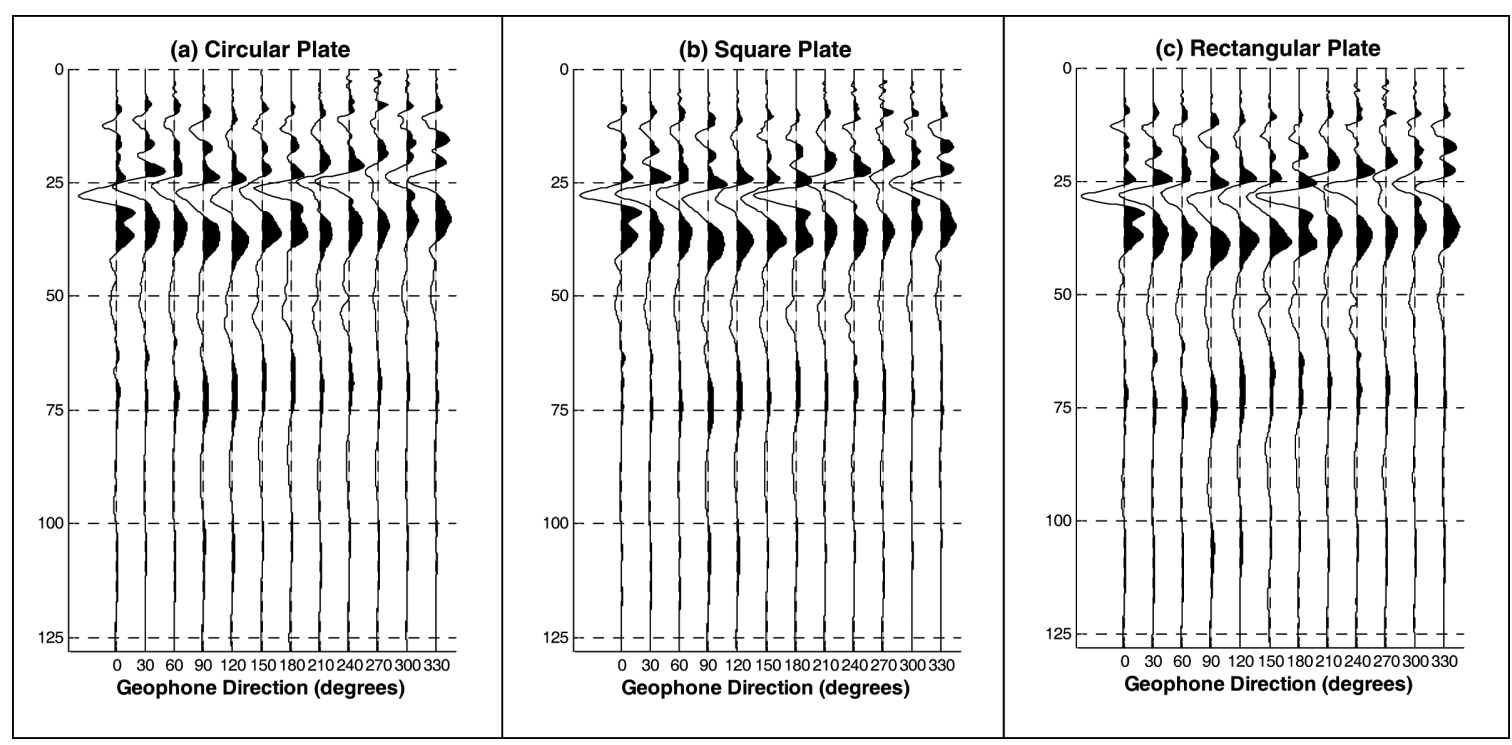

Fig. 4. Seismic waves obtained by circular geophone arrays. (a) Seismic wave signals by circular plate, (b) seismic wave signals by square plate and (c) seismic wave signals by rectangular plate.

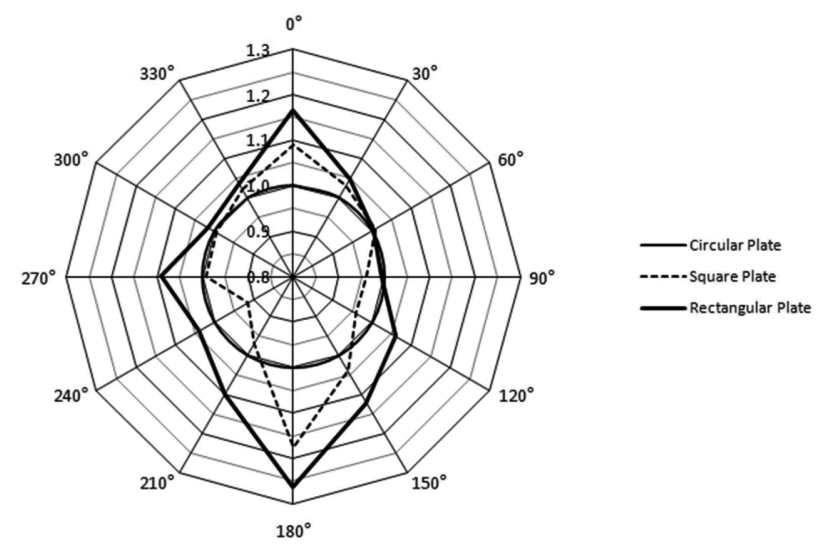

Fig. 5. Comparison of energy radiations. Energy increases in the direction of $0^{\circ}$ and $180^{\circ}$ when square or rectangular plate is used. Approximately 10-20\% more signal power is observed than when circular plate is used.

the autoregressive model (Kay and Marple, 1981), and the signal power is calculated by integrating PSD.

Figure 6 compares PSD and signal power when the long side direction of the rectangular plate coincides with the survey line. Circular and square plates show PSD peak value around $80 \mathrm{~Hz}$, whereas rectangular plate a slightly smaller value of $75 \mathrm{~Hz}$; the rectangular plate shows more rapid rise and fall around the peak than that of the other shapes of plates. Signal power was the largest with the value of $40.54 \mathrm{~dB}$ when the square plate was used, the smallest with the value of
$39.68 \mathrm{~dB}$ when the rectangular plate was used. About $17 \%$ less energy was observed when the rectangular plate was used instead of the square plate.

Figure 7 compares PSD and signal power when the long side direction of the rectangular plate normal to the survey line; the rectangular plate shows its peak around a slightly larger value of $90 \mathrm{~Hz}$. Peak frequency also increased when the plate was rotated $90^{\circ}$ from Fig. 6. Signal power was measured to be the largest with the value of $41.07 \mathrm{~dB}$ when the rectangular plate was used. About $15 \%$ more energy 

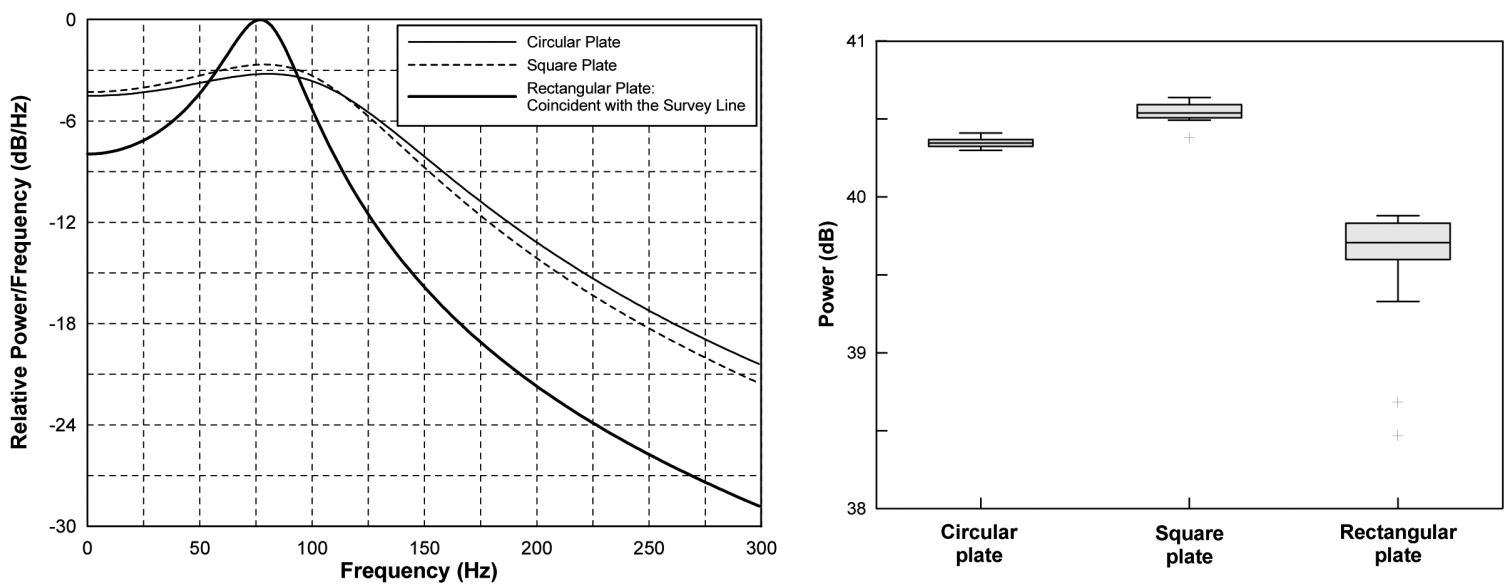

Fig. 6. Comparsion of PSD and signal power of seismic waves caused by hammer impacts with three shapes of plates. The geophone is located at $3 \mathrm{~m}$ from the source with the direction coincident with the long side of the rectangular plate.
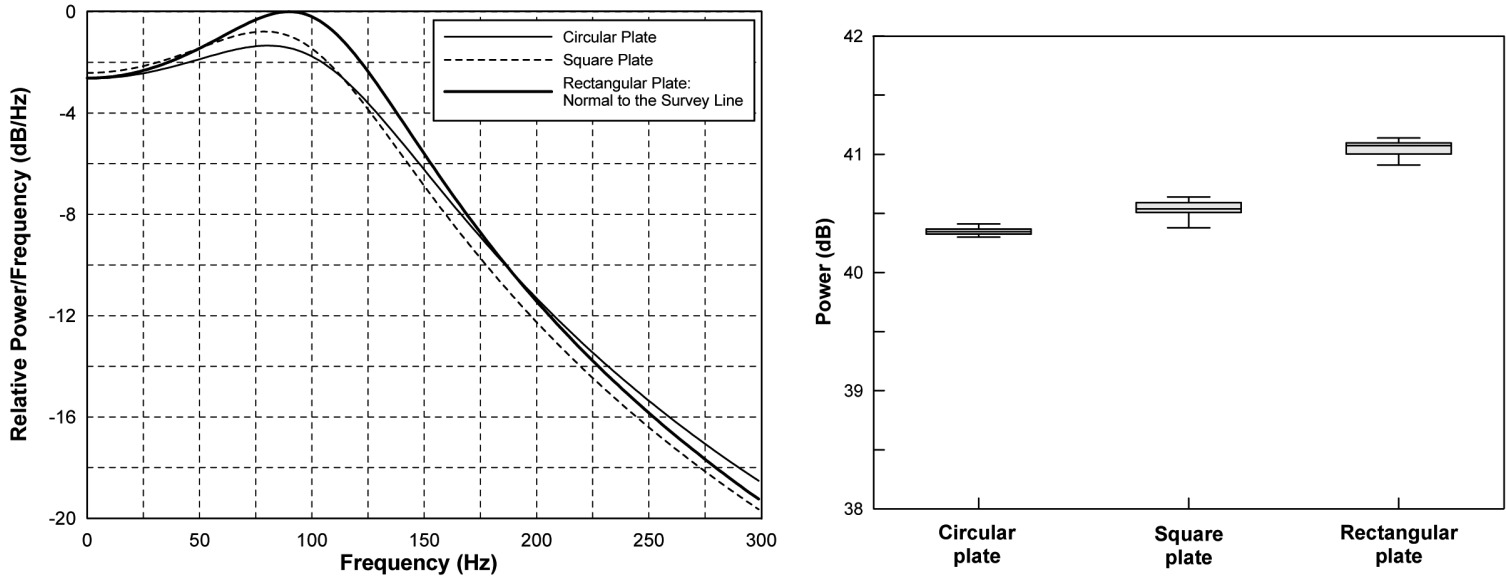

Fig. 7. Comparison of PSD and signal power of seismic waves caused by hammer impacts with three shapes of plates. The geophone is located at $3 \mathrm{~m}$ from the source with the direction normal to the long side of the rectangular plate.

was observed when the rectangular plate was used instead of the circular plate. This increase of power can be considered as the long side of the plate makes more elastic region on the ground and the shorter propagation in plastic plate caused to be less attenuation.

From this experiment, the highest frequency band and the largest signal power can be achieved when the long side direction of the rectangular plate is normal to the survey line.

\section{Conclusions}

This study looked into the characteristics of seismic wave propagation by comparing the PSD and signal power for three differently shaped (circular, square, rectangular) plates with the same weight. The conclusions of this study are as follows.

(1) A rectangular plate generally produced larger signal power in most of directions than a circular or a square plate. 
(2) Seismic wave with higher frequency band and larger signal power is achieved with a rectangular plate with the long side direction normal to the survey line than a circular or a square plate.

Therefore, the use of rectangular plate is recommended in a small scale seismic survey instead of circular or square plate. To solve the problem of insufficient energy when conducting small scale seismic survey, more research is needed such as that on using a different material with larger rebound coefficient than the PE material used as plate, or that on investigating the energy enhancement effect caused by plate stacking.

\section{Acknowledgment}

This work was supported by the Dong-A University research fund. We deeply appreciate reviewers for sparing their precious time for pointing out our mistakes on the manuscript.

\section{References}

Buhnemann, J. and Holliger, K., 1998, Comparison of high-frequency seismic sources at the Grimsel test site, central Alps, Switzerland. Geophysics, 63, 1363-1370.

Doll, W.E., Miller, R.D., and Xia, J., 1998, A noninvasive shallow seismic source comparison on the Oak Ridge Reservation, Tennessee. Geophysics, 63, 1318-1331.

Hearn, S.J. and Kay, M.H., 1991, Evaluation of P- and S- wave sources for shallow seismic reflection. Exploration Geophysics, 22, 169-174.

Kay, S.M. and Marple, S.L., 1981, Spectrum analysis-A modern perspective. Proceedings of the IEEE, 69, 13801419.

Kim, J.H. and Lee, Y.H., 2011, Comparison of Signal Powers Generated with Metal Hammer Plate and Plastic Hammer Plate. Jigu-Mulli-wa-Mulli-Tamsa, 14, 282-288.

Kim, J.Y., Kim, K.S., Kim, Y.S., Hyun, H.J., and Sung, N.H., 1994a, Development of Seismic Sources for Shallow Seismic Surveys. Journal of the Korean Institute of Mineral and Energy Resources Engineering, 31, 248-257.

Kim, J.Y., Kim, Y.S., Hyun, H.J., and Kim, K.S., 1994b, Application of $\mathrm{P}$ beam source to the shallow reflection seismics. Journal of the Korean Institute of Mineral and Energy Resources Engineering, 31, 407-412.

Knapp, R.W. and Steeples, D.W., 1986, High-resolution common-depth-point seismic reflection profiling instrumentation. Geophysics, 51, 276-282.

Mereu, R.F., Uffen, R.J., and Beck, A.E., 1963, The use of a coupler in the conversion of impact energy into seismic energy. Geophysics, 18, 531-546.

Miller, R.D., Pullan, S.E., Steeples, D.W., and Hunter, J.A., 1992, Field comparison of shallow seismic sources near Chino California. Geophysics, 57, 693-709.

Miller, R.D., Pullan, S.E., Steeples, D.W., and Hunter, J.A., 1994, Field comparison of shallow P-wave seismic sources near Houston, Texas. Geophysics, 59, 17131728.

Miller, R.D., Pullan, S.E., Waldner, J.S., and Haeni, F.P., 1986, Field comparison of shallow seismic sources. Geophysics, 51, 2067-2092.

Milsom, J., 2008, Field Geophysics, 3rd Ed. John Wiley and Sons, Ltd., London, UK, 232 p. 